\title{
Magnetic Resonance Imaging (MRI) Results Following Discontinuation of Methotrexate in Rheumatoid Arthritis Treated with Subcutaneous Tocilizumab: The COMP-ACT MRI Substudy
}

\author{
Charles Peterfy, Joel Kremer, William Rigby, Nora Singer, Christine Birchwood, Darcy Gill, \\ William Reiss, Jinglan Pei, and Margaret Michalska
}

\begin{abstract}
Objective. To assess differences in joint damage and inflammation using magnetic resonance imaging (MRI) between patients with rheumatoid arthritis (RA) who achieved low disease activity with tocilizumab (TCZ) + methotrexate (MTX) and subsequently continued or discontinued MTX.

Methods. In the COMP-ACT trial, US patients with RA received subcutaneous TCZ $162 \mathrm{mg}+$ MTX. Those who achieved 28-joint count Disease Activity Score calculated with erythrocyte sedimentation rate $(\mathrm{DAS} 28-\mathrm{ESR}) \leq 3.2$ at Week 24 were randomized 1:1 (double-blind) to discontinue MTX (TCZ monotherapy; mono) or continue TCZ + MTX until Week 52. In a subset of patients, 1.5-Tesla MRI was used to obtain images of bilateral hands and wrists at weeks 24 and 40 . Outcomes included changes in MRI-assessed synovitis, osteitis, erosion, and cartilage loss from Week 24 to Week 40, and in the proportion of patients with progression of each score.

Results. Of 296 patients who achieved DAS28-ESR $\leq 3.2$ at Week 24, 79 were enrolled in the pilot MRI substudy and randomized to TCZ mono $(n=38)$ or TCZ + MTX $(n=41)$. Treatment with either TCZ mono or TCZ + MTX suppressed erosion progression, synovitis, osteitis, and cartilage loss. The proportion of patients with no progression in each outcome measure was similar between groups (range, TCZ mono: 84.8-97.0\%; TCZ + MTX: 92.3-100\%).

Conclusion. In a subset of patients who achieved low disease activity with TCZ + MTX, MRI changes were minimal in intraarticular inflammation and damage measures in patients who discontinued MTX versus those who continued TCZ + MTX. (First Release November 1 2019; J Rheumatol 2020;47:325-32; doi:10.3899/jrheum.180953)
\end{abstract}

Key Indexing Terms:

RHEUMATOID ARTHRITIS MAGNETIC RESONANCE IMAGING BIOLOGIC THERAPY

From Spire Sciences Inc., Boca Raton, Florida; Albany Medical College and The Center for Rheumatology, Albany, New York; Geisel School of Medicine, Dartmouth College, Lebanon, New Hampshire; Case Western Reserve University and MetroHealth System, Cleveland, Ohio; Genentech Inc., South San Francisco, California, USA.

This study was funded by Genentech Inc.

C. Peterfy is a consultant for Roche and an employee of Spire Sciences Inc. J. Kremer is a shareholder of Corrona LLC, and a consultant for AbbVie, Amgen, Bristol-Myers Squibb, Eli Lilly and Co., Genentech Inc., GlaxoSmithKline, Pfizer, Regeneron, and Sanofi. W. Rigby is a consultant for Roche/Genentech. N. Singer is a consultant for Genentech. D. Gill, W. Reiss, J. Pei, and M. Michalska are employees of Genentech Inc.

C. Birchwood was an employee of Genentech Inc. at the time of this study.

C. Peterfy, MD, Spire Sciences Inc.; J. Kremer, MD, Albany Medical College and The Center for Rheumatology; W. Rigby, MD, Geisel School of Medicine, Dartmouth College; N. Singer, MD, Case Western Reserve University and MetroHealth System; C. Birchwood, PhD, Genentech Inc.; D. Gill, BS, Genentech Inc.; W. Reiss, PharmD, Genentech Inc.; J. Pei, BS, Genentech Inc.; M. Michalska, MD, Genentech Inc.

Address correspondence to Dr. C. Peterfy, Spire Sciences Inc., 5314 Boca Marina Circle North, Boca Raton, Florida 33487, USA.

E-mail: Charles.peterfy@spiresciences.com

Full Release Article. For details see Reprints and Permissions at jrheum.org

Accepted for publication May 17, 2019.
Magnetic resonance imaging (MRI) can detect changes in bone erosion with greater sensitivity than radiography and is an effective way to assess synovitis and osteitis in patients with rheumatoid arthritis (RA) $)^{1,2,3}$. Synovitis and osteitis have been shown to predict subsequent radiographic progression and structural deterioration in patients with $\mathrm{RA}^{4,5,6,7}$. Further, patients with RA who achieve remission based on the 28-joint count Disease Activity Score (DAS28) may still have synovitis, which in turn may lead to joint damage ${ }^{6,8,9}$, and possibly result in permanent disability $8,10,11$. The sensitivity of MRI allows for early detection of RA disease progression, provides a more sensitive evaluation of disease activity, and can detect therapeutic response in a shorter observation time $e^{1,12,13}$.

Although methotrexate (MTX) is often administered in combination with biologics to treat RA, it may be discontinued because of intolerance or to reduce the medication burden. Real-world studies have shown that about one-third of patients with RA who require biologic therapy receive it as monotherapy ${ }^{14,15,16}$, often because of MTX intol-

Personal non-commercial use only. The Journal of Rheumatology Copyright @ 2020 . All rights reserved. 
erance $^{17,18,19}$. Tocilizumab (TCZ) is a humanized monoclonal antibody against the interleukin (IL)-6 receptor and has been proven to be safe and effective in patients with RA, either in combination with MTX or as monotherapy ${ }^{20-29}$. Previous studies have shown that TCZ in combination with MTX or as monotherapy inhibits radiographic progression in patients with RA ${ }^{13,21,29,30}$; however, changes in active intraarticular inflammation after discontinuation of MTX in patients achieving good clinical control with TCZ + MTX have not been evaluated. In addition, only 1 study has evaluated radiographic data in patients receiving subcutaneous TCZ $(\mathrm{TCZ}-\mathrm{SC})^{31}$, and only 1 study has evaluated joint damage using MRI in patients receiving TCZ-SC ${ }^{30}$.

In a randomized, phase IV noninferiority study (COMP-ACT), patients with RA who achieved low disease activity (LDA) with TCZ + MTX and subsequently discontinued MTX had similar outcomes compared with patients who continued MTX ${ }^{32}$. The mean change in DAS28 calculated with erythrocyte sedimentation rate (DAS28-ESR) 16 weeks after discontinuation of MTX was similar between patients who received TCZ as monotherapy and those who received TCZ + MTX. The current substudy used MRI to assess differences in active intraarticular inflammation and joint damage by comparing the changes in MRI scores from Week 24 to Week 40 between patients with RA who had achieved LDA with TCZ + MTX and then either continued or discontinued MTX.

\section{MATERIALS AND METHODS}

Study design. COMP-ACT was a randomized, multicenter, double-blind, parallel-group, 52-week study (plus an 8-week followup) that compared TCZ + MTX with TCZ + placebo (TCZ monotherapy; mono) in patients with RA (Figure 1). This trial is registered on ClinicalTrials.gov: NCT01855789. A full description of the methods and patients has been described previously ${ }^{32}$ At baseline (Week 0), all patients received TCZ-SC $162 \mathrm{mg}$ [weekly (qw) for patients weighing $\geq 100 \mathrm{~kg}$ or every 2 weeks (q2w) for patients weighing $<100 \mathrm{~kg}$ ]; patients continued to receive their stable pre-baseline dose of open-label, oral MTX $\geq 15 \mathrm{mg} /$ week. Patients receiving TCZ-SC q2 w who did not achieve DAS28-ESR $\leq 3.2$ at Week 12 could increase the dosing frequency to weekly. At Week 24, patients who achieved DAS28-ESR $\leq 3.2$ were randomized 1:1 (double-blind) to either continue MTX (TCZ + MTX) or discontinue MTX (TCZ mono) through Week 52. A subset of these randomized patients was included in the MRI substudy.

This study was approved by the Copernicus Group Independent Review Board, Durham, North Carolina (tracking number INV2-13-154), and the institutional review boards and independent ethics committees of the investigational centers (160 centers with about 70 centers included in the MRI substudy). All patients provided written informed consent in accordance with the Declaration of Helsinki.

Patients. Patients aged $\geq 18$ years and weighing $\leq 150 \mathrm{~kg}$ with moderate to severe RA (DAS28-ESR $\geq 4.4$ ) according to the revised 1987 American College of Rheumatology criteria were included. Full inclusion and exclusion criteria have been described ${ }^{32}$. Patients were required to have an inadequate response to MTX, and up to about $20 \%$ of patients could have received a single tumor necrosis factor inhibitor $\geq 6$ months prior to screening. Patients were enrolled in the MRI substudy based on whether their location of enrollment was an MRI study site. MRI participation was a stratification factor at the time of randomization.

Assessments and outcomes. Both hands and wrists were imaged using
1.5-Tesla (T) MRI at weeks 24 and 40 only (no MRI was performed at baseline). The dominant hand was defined as the operant hand generally used for performing fine motor skills tasks (e.g., writing). All participating sites received training related to MRI technique and patient positioning. A commercial coil was used, which allowed coverage of the entire hand and wrist in a single field of view. A specially designed acrylic M-frame was used to facilitate proper and reproducible positioning ${ }^{33}$. The MRI protocol included coronal short-tau inversion recovery (STIR); coronal T1-weighted, 3-D gradient-echo with spectral fat suppression; and axial STIR; no gadolinium contrast was used. The right hand and wrist were imaged simultaneously followed by the left hand and wrist.

Two independent radiologists evaluated the images at a central reading facility using the Outcome Measures in Rheumatology Clinical Trials-Rheumatoid Arthritis Magnetic Resonance Imaging Score (OMERACT-RAMRIS) system ${ }^{34}$ to assess bone erosion, synovitis, and osteitis, and the 9-point cartilage loss scale (CARLOS) to assess cartilage $\operatorname{loss}^{35}$. Radiologists were blinded to visit order and treatment group. Changes in bone erosion, synovitis, osteitis, and cartilage loss occurring between Week 24 and Week 40 were measured. The smallest detectable change (SDC) was calculated to differentiate true change from interreader variability and was based on the SD of the differences between the change scores of the 2 MRI reviewers ${ }^{36}$. The thresholds for significant change at the individual patient level based on the SDC were 1.0 for bone erosion, 1.4 for osteitis, 0.9 for synovitis, and 0.6 for cartilage loss.

Statistical analyses. Based on historical data from the ACT-RAY study ( $0.2 \mathrm{~T}$ MRI of the more symptomatic hand and wrist $)^{13}$, it was established that 30 patients per arm would permit estimation of the $95 \%$ CI for group differences in the change in bone erosion score from Week 24 to Week 40 to within \pm 1.7 units, synovitis score to within \pm 0.98 units, and osteitis score to within \pm 2.88 units; no historical data were available at the time of study design to evaluate the efficacy of the planned sample size for the MRI endpoint of cartilage loss. Baseline demographics and clinical characteristics were summarized using descriptive statistics. The mean changes in MRI scores from Week 24 to Week 40 for each treatment arm and the difference in the means between treatment arms were estimated based on analysis of covariance adjusted for the stratification factors used in randomization. Cumulative probability plots of the changes in scores (bone erosion, synovitis, osteitis, and cartilage loss) from Week 24 to Week 40 were produced. The number and percentage of patients with progression from Week 24 to Week 40 on each assessment as determined by worsening that was greater than the SDC were summarized.

\section{RESULTS}

Baseline demographics and clinical characteristics. Of the 296 patients who achieved DAS28-ESR $\leq 3.2$ at Week 24 and were randomized to receive either TCZ mono or TCZ + MTX, 79 were included in the MRI substudy. A total of 38 patients received TCZ mono, and 41 received TCZ + MTX. Baseline demographics were similar between treatment groups in the MRI substudy and between patients in the MRI substudy and the overall study population (Table 1).

MRI analysis. At Week 24 (randomization), MRI scores were similar between treatment groups (Table 2). At Week 40, patients receiving either TCZ mono or TCZ + MTX had minimal numerical changes in synovitis, osteitis, bone erosion, or cartilage loss (Table 3). The 95\% CI of the difference in the changes in MRI scores between the TCZ mono and TCZ + MTX groups crossed zero for bone erosion, synovitis, osteitis, and cartilage loss, suggesting that there was no clinically meaningful difference between groups. Although data from ACT-RAY were used to estimate the

Personal non-commercial use only. The Journal of Rheumatology Copyright @ 2020 . All rights reserved 


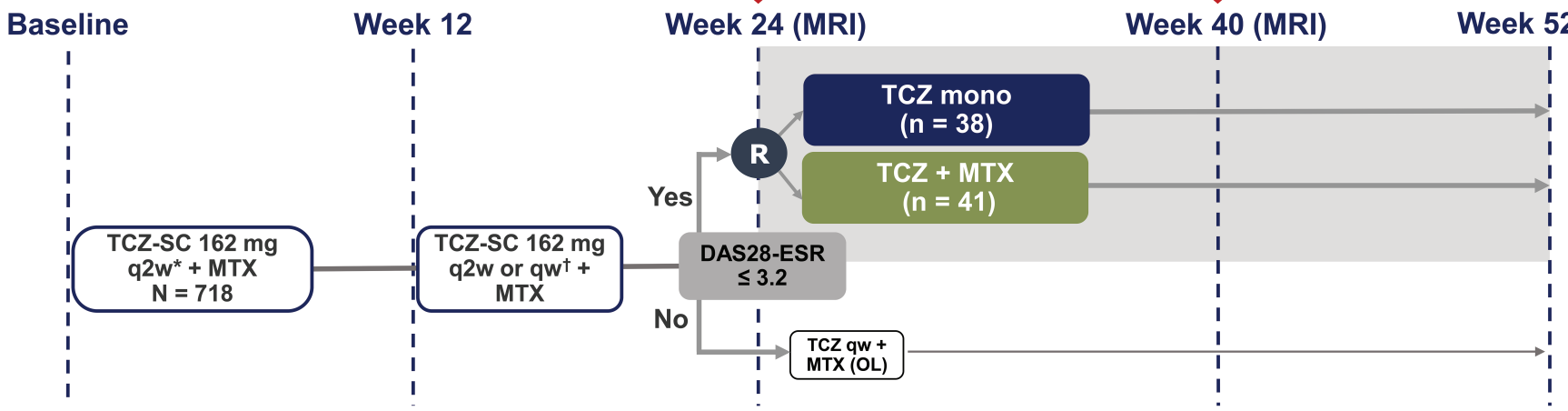

Figure 1. Study design. Open-label TCZ-SC was administered for the entire study duration; MTX discontinuation was maintained in a blinded fashion after Week 24. * If patient weight $\geq 100 \mathrm{~kg}$, start TCZ-SC qw. $\dagger$ If DAS28-ESR > 3.2, increase frequency to qw. DAS28-ESR: 28-joint count Disease Activity Score calculated with erythrocyte sedimentation rate; mono: monotherapy; MRI: magnetic resonance imaging; MTX: methotrexate; q2w: every 2 weeks; qw: every week; OL: open label; R: randomization; SC: subcutaneous; TCZ: tocilizumab.

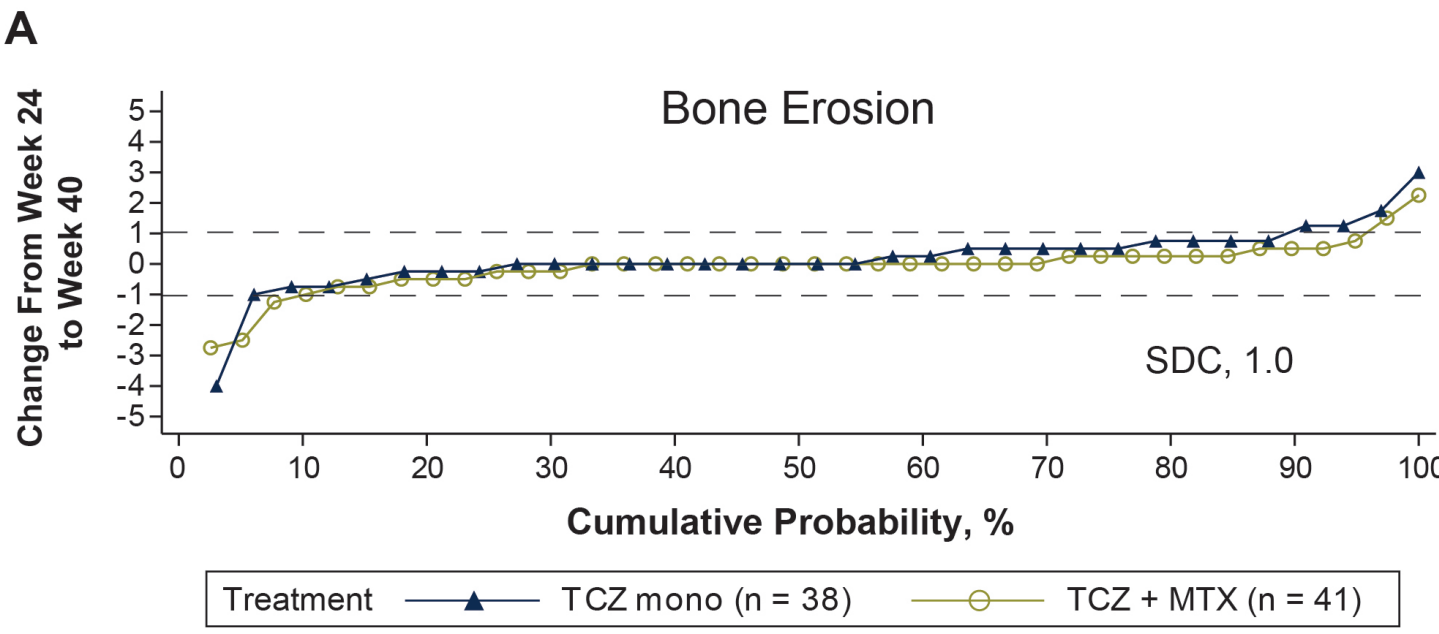

B

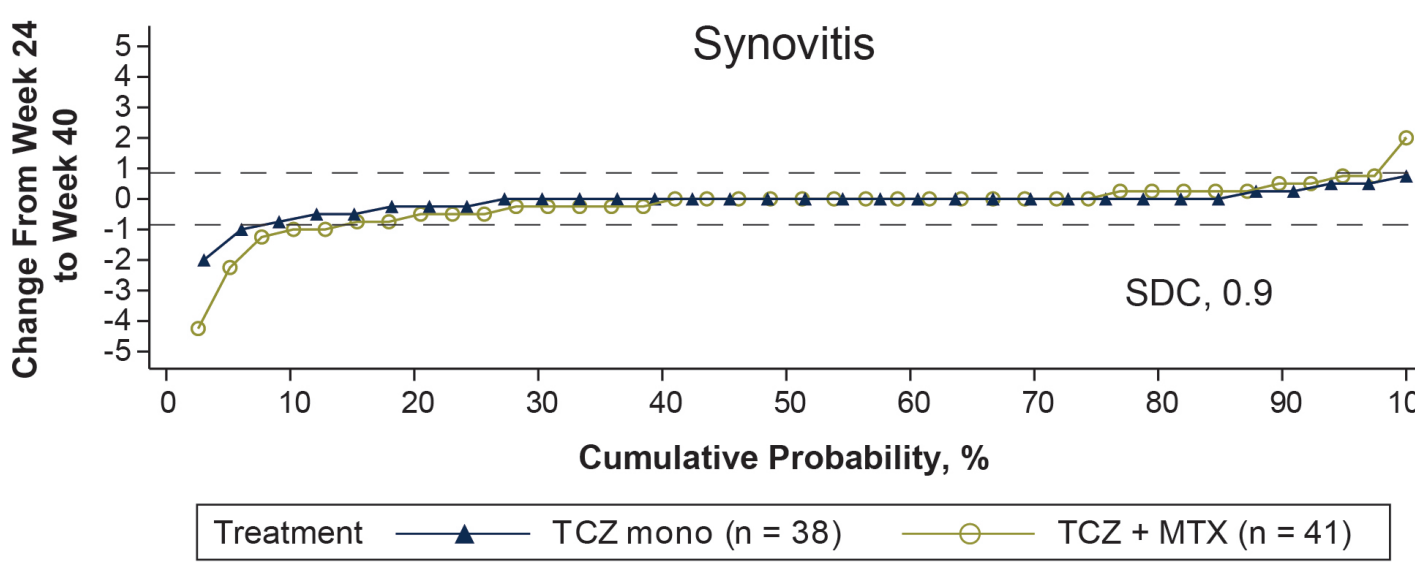

Figure 2. Individual patient bilateral MRI scores. A. Bone erosion. B. Synovitis. C. Osteitis. D. Cartilage loss. Mono: monotherapy; MRI: magnetic resonance imaging; MTX: methotrexate; SDC: smallest detectable change; TCZ: tocilizumab. 


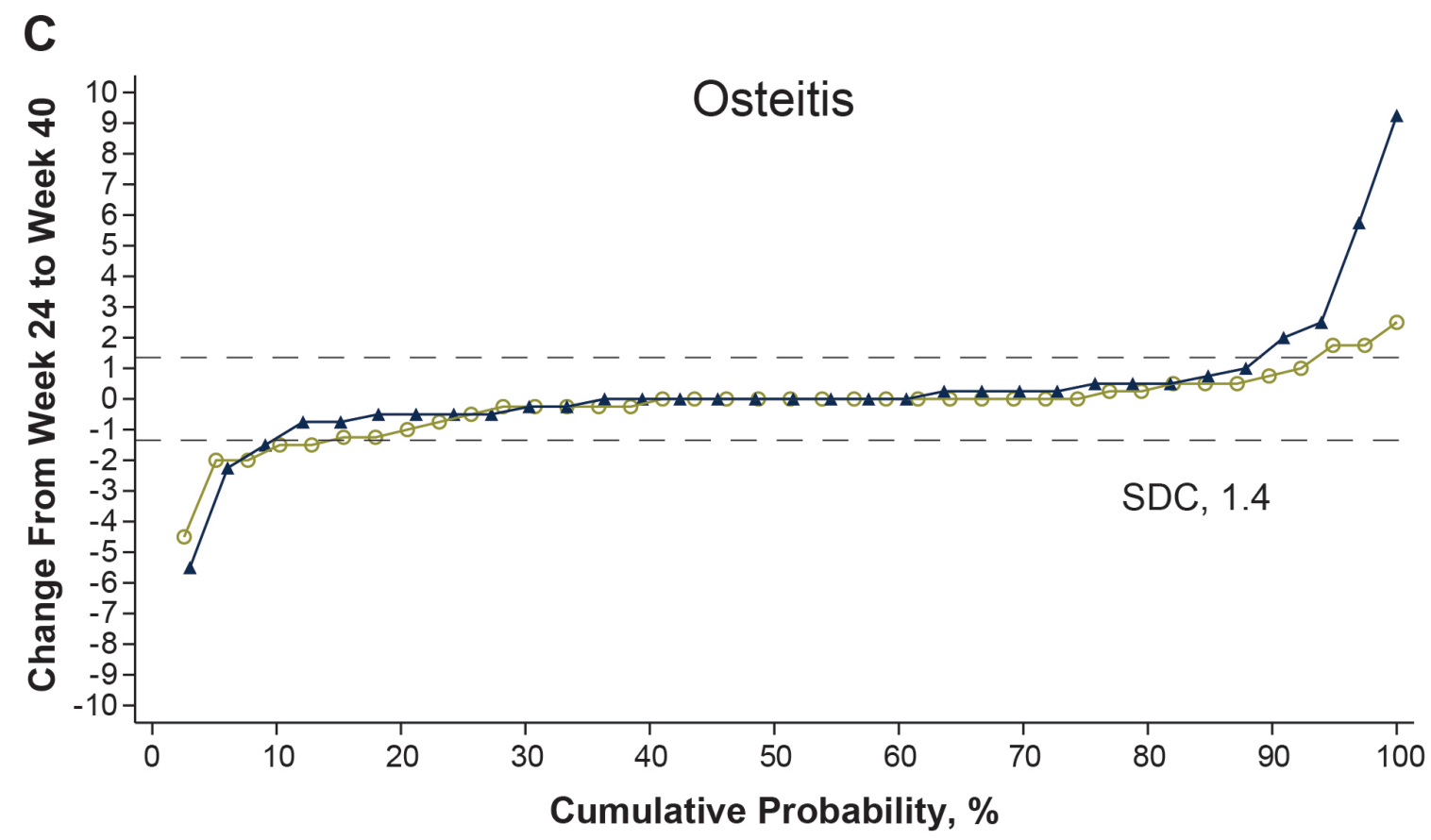

Treatment $\longrightarrow \operatorname{TCZ}$ mono $(\mathrm{n}=38) \longrightarrow \mathrm{TCZ}+\operatorname{MTX}(\mathrm{n}=41)$

D

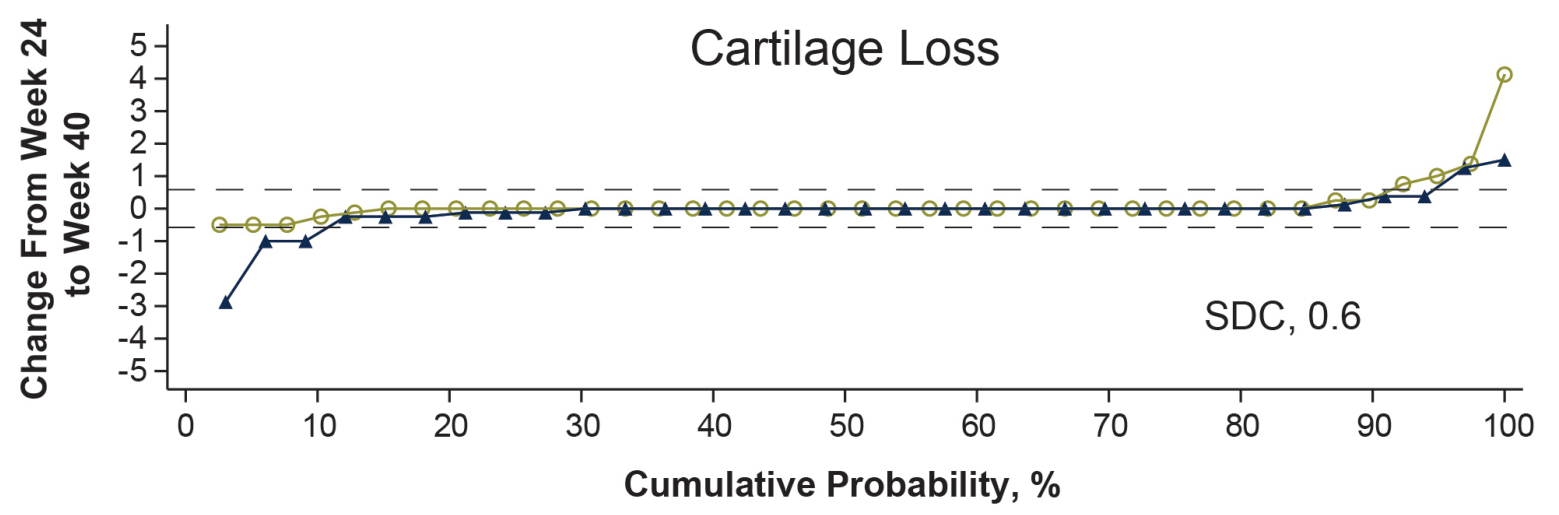

Treatment $\longrightarrow$ TCZ mono $(n=38) \longrightarrow \quad$ TCZ + MTX $(n=41)$

Figure 2. Continued.

sample size needed to permit estimation of the $95 \%$ CI to detect group differences, the present study was not powered to discriminate statistical differences in the changes between these groups. MRI results were consistent for bilateral hands and wrists and for the dominant hand and wrist, but the changes in erosion and osteitis were numerically slightly greater on the dominant side. Cumulative probability plots showed no major outliers for change greater than the SDC in erosion, synovitis, and cartilage loss (Figure 2), but 2 patients in the TCZ mono group showed relatively large changes in osteitis (5.75 and 9.25; Figure 2C).
The majority of patients in both treatment groups had no MRI progression in both hands at Week 40; this was also seen in the dominant hand and wrist (Figure 3). Differences between groups in the proportion of patients with no progression in the dominant hand in each outcome measure were small (range, TCZ + MTX: 92.3\%-100\%; TCZ mono: $84.8 \%-97.0 \%)$.

\section{DISCUSSION}

This COMP-ACT trial substudy used MRI to measure bone erosion, synovitis, osteitis, and cartilage loss. Treatment with 
Table 1. Baseline demographics and clinical characteristics.

\begin{tabular}{lccc}
\hline Characteristics & $\begin{array}{c}\text { TCZ Mono, } \\
\mathrm{n}=38\end{array}$ & $\begin{array}{c}\mathrm{TCZ}+\mathrm{MTX}, \\
\mathrm{n}=41\end{array}$ & $\begin{array}{c}\text { Total } \\
\text { Patients, } \\
\mathrm{N}=294 *\end{array}$ \\
& & & \\
\hline Female, $\mathrm{n}(\%)$ & $29(76.3)$ & $30(73.2)$ & $220(74.8)$ \\
Age, yrs & $54.2(14.0)$ & $58.3(11.3)$ & $55.5(12.6)$ \\
Duration of RA, yrs & $6.8(6.4)$ & $7.0(8.3)$ & $6.8(7.7)$ \\
RF-positive, n (\%) & $33(86.8)$ & $31(75.6)$ & $212(72.1)$ \\
ACPA-positive, n (\%) & $33(86.8)$ & $31(75.6)$ & $223(75.9)$ \\
Weight, kg & $79.1(18.7)$ & $78.6(14.7)$ & $81.7(18.8)$ \\
BMI, kg/m & $29.7(6.8)$ & $28.2(5.2)$ & $29.9(6.4)$ \\
No. previous DMARD & $1.3(0.4)$ & $1.3(0.5)$ & $1.2(0.5)$ \\
Baseline MTX dose, mg/week & $18.0(3.0)$ & $18.5(3.1)$ & $17.9(3.2)$ \\
No. previous TNFi & $0.2(0.4)$ & $0.2(0.4)$ & $0.2(0.4)$ \\
Oral corticosteroid use, $\mathrm{n}(\%)$ & $15(39.5)$ & $17(41.5)$ & $111(37.8)$ \\
Baseline corticosteroid dose, & & & \\
$\quad$ & & & \\
$\quad$ mg/day & $6.4(2.7)$ & $6.6(2.5)$ & $6.6(2.7)$ \\
DAS28-ESR & $6.4(1.1)$ & $6.2(0.9)$ & $6.3(0.9)$ \\
CDAI & $37.4(12.1)$ & $38.5(13.5)$ & $38.2(12.3)$ \\
SDAI & $39.3(12.3)$ & $39.3(13.7)$ & $39.3(12.5)$ \\
\hline
\end{tabular}

Values are mean (SD) unless otherwise specified. * Two of the 296 randomized patients were not treated after Week 24; therefore, 294 randomized patients were included in the intent-to-treat population. ACPA: anticyclic citrullinated peptide antibody; BMI: body mass index; CDAI: Clinical Disease Activity Index; DAS28-ESR: 28-joint count Disease Activity Score calculated with erythrocyte sedimentation rate; DMARD: disease-modifying antirheumatic drug; mono: monotherapy; MTX: methotrexate; RA: rheumatoid arthritis; RF: rheumatoid factor; SDAI: Simplified Disease Activity Index; TCZ: tocilizumab; TNFi: tumor necrosis factor inhibitor.

Table 2. Bilateral MRI scores* at randomization (Week 24). Values are mean (SD).

\begin{tabular}{lcc}
\hline & TCZ Mono, $\mathrm{n}=38$ & TCZ + MTX, $\mathrm{n}=41$ \\
\hline Bone erosion (0-250) & $9.1(7.9)$ & $10.7(11.2)$ \\
Synovitis (0-24) & $2.3(2.0)$ & $3.4(3.3)$ \\
Osteitis (0-75) & $2.3(3.9)$ & $2.5(3.1)$ \\
Cartilage loss (0-100) & $4.7(6.4)$ & $5.7(8.2)$ \\
\hline
\end{tabular}

* Bilateral MRI scores were averaged over both hands. Mono: monotherapy; MRI: magnetic resonance imaging; MTX: methotrexate; TCZ: tocilizumab. either TCZ + MTX or TCZ mono in patients with RA who had achieved LDA with TCZ + MTX suppressed synovitis, osteitis, cartilage loss, and erosion progression. Although therapy with TCZ + MTX showed numerically greater suppression of bone erosion (difference of 0.24 on a scale of $0-250)$, synovitis $(0.06$ on a scale of $0-24)$, osteitis $(0.53$ on a scale of $0-75)$, and cartilage loss $(-0.23$ on a scale of $0-100$; Table 3) compared with TCZ mono, the study was not powered to discriminate small differences between the 2 groups.

The present study differs from prior MRI studies involving TCZ mono. In the phase IIIb ACT-RAY study, which included patients with inadequate response to MTX (DAS28 $>4.4$ at baseline), a subset of patients underwent MRI of the more symptomatic hand and wrist at weeks $0,2,12$, and 52, and radiography of the hands/wrists and feet at weeks 0,24 , and $52^{13}$. Patients were receiving MTX prior to baseline and either switched to intravenous (IV) TCZ mono $(n=32)$ or continued MTX and added TCZ-IV (TCZ + MTX; $n=31$ ), as opposed to the present study in which patients achieved LDA while receiving TCZ + MTX then discontinued MTX (Week 24). In the open-label AC-CUTE study, 52 patients received either TCZ-SC mono or TCZ in combination with MTX or other conventional synthetic disease-modifying antirheumatic drugs (DMARD). Patients underwent MRI of the dominant hand and radiography of the hands, wrists, and feet at weeks 0 and $24^{30}$. Erosion and cartilage loss scores at Week 24 in the present study were similar to those at baseline in the AC-CUTE study (erosion: 8.4-9.9; cartilage loss: 4.8-9.2), but erosion scores were lower than those at baseline in the ACT-RAY MRI substudy $(16.0-19.4)^{13,30}$. The synovitis and osteitis scores at Week 24 in the present study were also less than half those observed at baseline in the prior studies (ACT-RAY synovitis: 7.2-7.4; ACT-RAY osteitis: 7.8-11.1; AC-CUTE synovitis: 4.3-4.6; AC-CUTE osteitis: 5.3-7.3). This is not surprising because the patients in COMP-ACT had already achieved clinical LDA with TCZ therapy by Week 24.

Table 3. Changes in MRI scores from Week 24 to Week 40 in patients receiving TCZ in combination with MTX or TCZ as monotherapy.

\begin{tabular}{|c|c|c|c|c|c|c|}
\hline Bone erosion $(0-250)$ & $0.18(0.19)$ & $-0.06(0.18)$ & 0.24 ( -0.21 to 0.68$)$ & $0.49(0.25)$ & $0.06(0.24)$ & $0.43(-0.14$ to 1.01$)$ \\
\hline Synovitis $(0-24)$ & $-0.18(0.15)$ & $-0.24(0.15)$ & $0.06(-0.30$ to 0.41$)$ & $-0.11(0.12)$ & $-0.22(0.12)$ & $0.11(-0.18$ to 0.40$)$ \\
\hline Osteitis $(0-75)$ & $0.37(0.36)$ & $-0.16(0.34)$ & $0.53(-0.30$ to 1.36$)$ & $0.69(0.54)$ & $-0.39(0.52)$ & $1.07(-0.18$ to 2.33$)$ \\
\hline
\end{tabular}

Values are mean (SE) unless otherwise indicated. * ANCOVA model for estimated means includes Week 24 bone erosion as a covariate, treatment group, and the following randomization stratification factors: DAS28-ESR remission status at Week $24(<2.6$ or $\geq 2.6$ to $\leq 3.2)$, patient TNFi exposure (yes or no), and baseline weight-by-dosing group ( $<80 \mathrm{~kg} \mathrm{q} 2 \mathrm{w}, 80$ to $<100 \mathrm{~kg} \mathrm{q} 2 \mathrm{w}, 80$ to $<100 \mathrm{~kg} \mathrm{qw}$, or $\geq 100 \mathrm{~kg} \mathrm{qw})$. Week 24 MRI scores were subtracted from Week 40 MRI scores, and a negative score indicates an improvement. DAS28-ESR: 28-joint count Disease Activity Score calculated with erythrocyte sedimentation rate; mono: monotherapy; MRI: magnetic resonance imaging; MTX: methotrexate; q2w: every 2 weeks; qw: once a week; SE: standard error; TCZ: tocilizumab; TNFi: tumor necrosis factor inhibitor. 


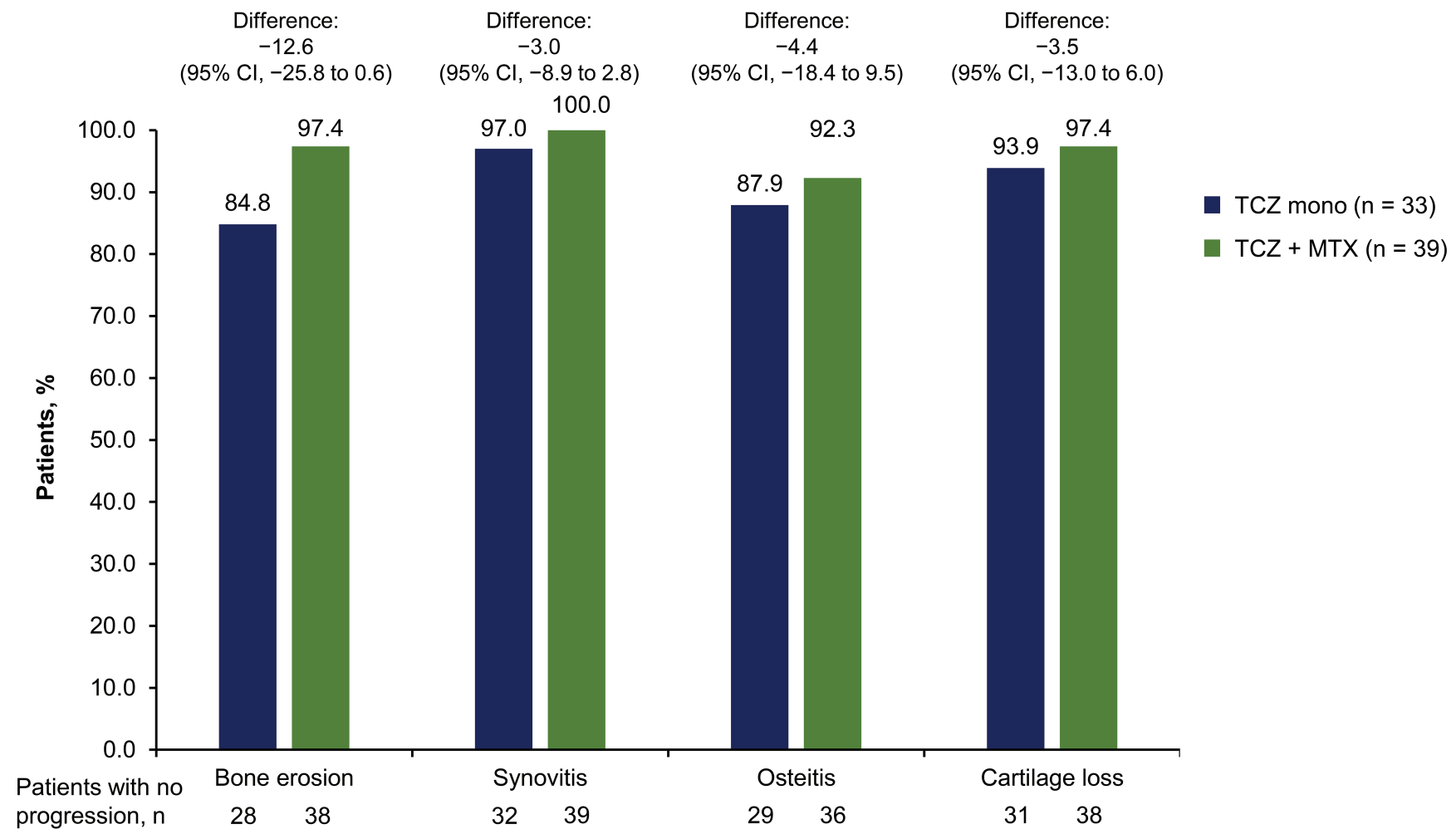

Figure 3. Percentage of patients not progressing more than the SDC in the dominant hand and wrist at Week 40. Mono: monotherapy; MTX: methotrexate; SDC: smallest detectable change; TCZ: tocilizumab.

In the present study, MRI scores were consistent between both hands and wrists and the dominant hand and wrist; however, the changes in erosion and osteitis, the precursor to erosion, were numerically slightly greater on the dominant side. The magnitude of the changes in synovitis and osteitis in the present study was less than those observed in the ACT-RAY MRI substudy and AC-CUTE study ${ }^{13,30}$. Each of those 2 studies showed significant decreases of about 2 units for synovitis and 4 units for osteitis, whereas the changes in the present study were small ( $<1$ unit). This difference is likely due to lower baseline severity of inflammation in these patients who had achieved LDA after 24 weeks of TCZ + MTX therapy in the open-label phase of the present study.

The difference in magnitude of changes also may be related to the shorter 16-week interval between MRI imaging in the present study than in prior studies. In the ACT-RAY MRI substudy, the most significant differences in synovitis and osteitis scores were measured after 52 weeks of therapy, but improvements in synovitis and osteitis scores were observed as early as 2 weeks. In the AC-CUTE study, MRI changes were measured after 24 weeks. The smaller decreases observed in synovitis may have been related to the present study not using gadolinium contrast, which increases sensitivity and specificity for synovitis. However, a smaller decrease was also seen for osteitis, which is most sensitively detected with gadolinium non-enhanced STIR imaging used in this study.

Including cartilage loss and bone erosion in this study allowed full MRI evaluation of structural damage to the joints, analogous to the radiographic total Sharp score used in clinical trials of patients with $\mathrm{RA}^{37}$. A large study of data pooled from several clinical trials concluded that cartilage loss was, in fact, a stronger determinant of disability than was erosion ${ }^{8}$. Additionally, while erosion and cartilage loss usually covary, the link between the two is not sufficiently strong to ensure that an effect observed on one is invariably happening to the other. Progression of erosion and joint space narrowing did not occur at the same rate in the ASPIRE study of infliximab ${ }^{38}$ and in a study of denosumab ${ }^{7}$. In both studies, erosion was strongly inhibited, whereas joint space narrowing continued to progress ${ }^{7,38}$.

The present study is unique in that bilateral hands and wrists were imaged using MRI. Patients with RA are characterized by symmetrical joint involvement, and both physical examination and radiographs are often performed on the bilateral hands and wrists. However, most clinical trials of RA using MRI have imaged only one side, usually the clinically most severe or dominant side ${ }^{13,30}$. The minimal clinical differences between the dominant hand and both hands in the present study are supported by a previous radiographic study

Personal non-commercial use only. The Journal of Rheumatology Copyright $@$ 2020. All rights reserved 
indicating more symmetry as RA progresses ${ }^{39}$. However, a large study evaluating handedness and severity of affected joints in patients with RA showed that the joints on the dominant side of right-handed patients were clinically and radiographically more affected; a similar pattern was seen in left-handed patients, but the sample size was small ${ }^{40}$. In contrast, a study using 3.0T MRI to image bilateral hands and wrists in patients with RA (median disease duration of 48 months) showed that the dominant hand was not always more severely affected than the nondominant hand based on MRI scores $^{41}$. In addition, the clinically most affected hand as chosen by patient complaint and physical examination may not be the most affected based on MRI. The aforementioned study reported poor concordance between physical examination and MRI scores; linear regression showed that the clinically more severe hands could not represent the contralateral hand to evaluate RAMRIS ${ }^{41}$. Imaging bilateral hands and wrists with MRI may prevent misdiagnosis that may result if only the dominant or most clinical hand and wrist are imaged.

Owing to the small sample size and small differences in the changes among the MRI features examined, this MRI substudy was not powered to show a clinically significant difference between treatments with TCZ + MTX and TCZ mono. In addition, gadolinium-based contrast was not used in this study, which might have decreased the sensitivity and specificity, particularly for synovitis evaluations; however, not using gadolinium contrast allowed reduction of the overall imaging time. Further, no baseline MRI was performed before treatment with TCZ, limiting the ability to assess the effect of TCZ on joint damage prior to the first MRI assessment. Finally, it is possible that 16 weeks is not long enough to determine the longterm effect of MTX discontinuation on joint damage.

In a subset of patients who achieved LDA with TCZ + MTX and were included in this MRI pilot substudy, minimal further MRI-assessed changes were observed in those who discontinued MTX and those who continued MTX.

\section{ACKNOWLEDGMENT}

Support for third-party writing assistance for this manuscript, furnished by Nicola Gillespie, DVM, of Health Interactions Inc., was provided by Genentech Inc.

\section{REFERENCES}

1. American College of Rheumatology Rheumatoid Arthritis Clinical Trials Task Force Imaging Group and Outcome Measures in Rheumatology Magnetic Resonance Imaging Inflammatory Arthritis Working Group. Review: the utility of magnetic resonance imaging for assessing structural damage in randomized controlled trials in rheumatoid arthritis. Arthritis Rheum 2013;65:2513-23.

2. Chen TS, Crues JV 3rd, Ali M, Troum OM. Magnetic resonance imaging is more sensitive than radiographs in detecting change in size of erosions in rheumatoid arthritis. J Rheumatol 2006; 33:1957-67.

3. McGonagle D, Conaghan PG, O'Connor P, Gibbon W, Green M, Wakefield $\mathrm{R}$, et al. The relationship between synovitis and bone changes in early untreated rheumatoid arthritis: a controlled magnetic resonance imaging study. Arthritis Rheum 1999; 42:1706-11.

4. Østergaard M, Emery P, Conaghan PG, Fleischmann R, Hsia EC, $\mathrm{Xu} \mathrm{W}$, et al. Significant improvement in synovitis, osteitis, and bone erosion following golimumab and methotrexate combination therapy as compared with methotrexate alone: a magnetic resonance imaging study of 318 methotrexate-naive rheumatoid arthritis patients. Arthritis Rheum 2011;63:3712-22.

5. Dougados M, Devauchelle-Pensec V, Ferlet JF, Jousse-Joulin S, D'Agostino MA, Backhaus M, et al. The ability of synovitis to predict structural damage in rheumatoid arthritis: a comparative study between clinical examination and ultrasound. Ann Rheum Dis 2013;72:665-71.

6. Hetland ML, Ejbjerg B, Hørslev-Petersen K, Jacobsen S, Vestergaard A, Jurik AG, et al; CIMESTRA study group. MRI bone oedema is the strongest predictor of subsequent radiographic progression in early rheumatoid arthritis. Results from a 2-year randomised controlled trial (CIMESTRA). Ann Rheum Dis 2009;68:384-90.

7. Cohen SB, Dore RK, Lane NE, Ory PA, Peterfy CG, Sharp JT, et al; Denosumab Rheumatoid Arthritis Study Group. Denosumab treatment effects on structural damage, bone mineral density, and bone turnover in rheumatoid arthritis: a twelve-month, multicenter, randomized, double-blind, placebo-controlled, phase II clinical trial. Arthritis Rheum 2008;58:1299-309.

8. Aletaha D, Smolen JS. Joint damage in rheumatoid arthritis progresses in remission according to the Disease Activity Score in 28 joints and is driven by residual swollen joints. Arthritis Rheum 2011;63:3702-11.

9. Brown AK, Quinn MA, Karim Z, Conaghan PG, Peterfy CG, Hensor E, et al. Presence of significant synovitis in rheumatoid arthritis patients with disease-modifying antirheumatic drug-induced clinical remission: evidence from an imaging study may explain structural progression. Arthritis Rheum 2006; 54:3761-73.

10. Drossaers-Bakker KW, de Buck M, van Zeben D, Zwinderman AH, Breedveld FC, Hazes JM. Long-term course and outcome of functional capacity in rheumatoid arthritis: the effect of disease activity and radiologic damage over time. Arthritis Rheum 1999;42:1854-60.

11. Smolen JS, Aletaha D. Patients with rheumatoid arthritis in clinical care. Ann Rheum Dis 2004;63:221-5.

12. Peterfy C, Østergaard M, Conaghan PG. MRI comes of age in RA clinical trials. Ann Rheum Dis 2013;72:794-6.

13. Conaghan PG, Peterfy C, Olech E, Kaine J, Ridley D, Dicarlo J, et al. The effects of tocilizumab on osteitis, synovitis and erosion progression in rheumatoid arthritis: results from the ACT-RAY MRI substudy. Ann Rheum Dis 2014;73:810-6.

14. Listing J, Strangfeld A, Rau R, Kekow J, Gromnica-Ihle E, Klopsch $\mathrm{T}$, et al. Clinical and functional remission: even though biologics are superior to conventional DMARDs overall success rates remain low - results from RABBIT, the German biologics register. Arthritis Res Ther 2006;8:R66.

15. Soliman MM, Ashcroft DM, Watson KD, Lunt M, Symmons DP, Hyrich KL, et al; British Society for Rheumatology Biologics Register. Impact of concomitant use of DMARDs on the persistence with anti-TNF therapies in patients with rheumatoid arthritis: results from the British Society for Rheumatology Biologics Register. Ann Rheum Dis 2011;70:583-9.

16. Felson DT, Smolen JS, Wells G, Zhang B, van Tuyl LH, Funovits J, et al. American College of Rheumatology/European League Against Rheumatism provisional definition of remission in rheumatoid arthritis for clinical trials. Ann Rheum Dis 2011;70:404-13.

17. Furst DE, Koehnke R, Burmeister LF, Kohler J, Cargill I. Increasing

Personal non-commercial use only. The Journal of Rheumatology Copyright (C) 2020. All rights reserved. 
methotrexate effect with increasing dose in the treatment of resistant rheumatoid arthritis. J Rheumatol 1989;16:313-20.

18. Schnabel A, Reinhold-Keller E, Willmann V, Gross WL. Tolerability of methotrexate starting with 15 or $25 \mathrm{mg} /$ week for rheumatoid arthritis. Rheumatol Int 1994;14:33-8.

19. Verstappen SM, Jacobs JW, van der Veen MJ, Heurkens AH, Schenk Y, ter Borg EJ, et al; Utrecht Rheumatoid Arthritis Cohort study group. Intensive treatment with methotrexate in early rheumatoid arthritis: aiming for remission. Computer Assisted Management in Early Rheumatoid Arthritis (CAMERA, an open-label strategy trial). Ann Rheum Dis 2007;66:1443-9.

20. Jones G, Wallace T, McIntosh MJ, Brockwell L, Gómez-Reino JJ, Sebba A. Five-year efficacy and safety of tocilizumab monotherapy in patients with rheumatoid arthritis who were methotrexate- and biologic-naive or free of methotrexate for 6 months: the AMBITION study. J Rheumatol 2017;44:142-6.

21. Dougados M, Kissel K, Sheeran T, Tak PP, Conaghan PG, Mola $\mathrm{EM}$, et al. Adding tocilizumab or switching to tocilizumab monotherapy in methotrexate inadequate responders: 24-week symptomatic and structural results of a 2-year randomised controlled strategy trial in rheumatoid arthritis (ACT-RAY). Ann Rheum Dis 2013;72:43-50.

22. Smolen JS, Beaulieu A, Rubbert-Roth A, Ramos-Remus C, Rovensky J, Alecock E, et al; OPTION Investigators. Effect of interleukin-6 receptor inhibition with tocilizumab in patients with rheumatoid arthritis (OPTION study): a double-blind, placebo-controlled, randomised trial. Lancet 2008;371:987-97.

23. Genovese MC, McKay JD, Nasonov EL, Mysler EF, da Silva NA, Alecock E, et al. Interleukin-6 receptor inhibition with tocilizumab reduces disease activity in rheumatoid arthritis with inadequate response to disease-modifying antirheumatic drugs: the tocilizumab in combination with traditional disease-modifying antirheumatic drug therapy study. Arthritis Rheum 2008;58:2968-80.

24. Emery P, Keystone E, Tony HP, Cantagrel A, van Vollenhoven R, Sanchez A, et al. IL-6 receptor inhibition with tocilizumab improves treatment outcomes in patients with rheumatoid arthritis refractory to anti-tumour necrosis factor biologicals: results from a 24-week multicentre randomised placebo-controlled trial. Ann Rheum Dis 2008;67:1516-23.

25. Jones G, Sebba A, Gu J, Lowenstein MB, Calvo A, Gomez-Reino $\mathrm{JJ}$, et al. Comparison of tocilizumab monotherapy versus methotrexate monotherapy in patients with moderate to severe rheumatoid arthritis: the AMBITION study. Ann Rheum Dis 2010;69:88-96

26. Kremer JM, Blanco R, Brzosko M, Burgos-Vargas R, Halland AM, Vernon E, et al. Tocilizumab inhibits structural joint damage in rheumatoid arthritis patients with inadequate responses to methotrexate: results from the double-blind treatment phase of a randomized placebo-controlled trial of tocilizumab safety and prevention of structural joint damage at one year. Arthritis Rheum 2011;63:609-21.

27. Burmester GR, Rubbert-Roth A, Cantagrel A, Hall S, Leszczynski P, Feldman D, et al. A randomised, double-blind, parallel-group study of the safety and efficacy of subcutaneous tocilizumab versus intravenous tocilizumab in combination with traditional disease-modifying antirheumatic drugs in patients with moderate to severe rheumatoid arthritis (SUMMACTA study). Ann Rheum Dis 2014;73:69-74.

28. Gabay C, Emery P, van Vollenhoven R, Dikranian A, Alten R, Pavelka K, et al. Tocilizumab monotherapy versus adalimumab monotherapy for treatment of rheumatoid arthritis (ADACTA): a randomised, double-blind, controlled phase 4 trial. Lancet 2013;381:1541-50.

29. Burmester GR, Rigby WF, van Vollenhoven RF, Kay J, Rubbert-Roth A, Blanco R, et al. Tocilizumab combination therapy or monotherapy or methotrexate monotherapy in methotrexate-naive patients with early rheumatoid arthritis: 2-year clinical and radiographic results from the randomised, placebo-controlled FUNCTION trial. Ann Rheum Dis 2017;76:1279-84.

30. Bird P, Peterfy C, Countryman P, Griffiths H, Barrett R, Youssef P, et al. AC-CUTE: An open-label study to evaluate progression of structural joint damage and inflammation in subjects with moderate to severe rheumatoid arthritis. Int J Rheumatol 2018;2018:8721753.

31. Kivitz A, Olech E, Borofsky M, Zazueta BM, Navarro-Sarabia F, Radominski SC, et al. Subcutaneous tocilizumab versus placebo in combination with disease-modifying antirheumatic drugs in patients with rheumatoid arthritis. Arthritis Care Res 2014;66:1653-61.

32. Kremer JM, Rigby W, Singer NG, Birchwood C, Gill D, Reiss W, et al. Sustained response following discontinuation of methotrexate in patients with rheumatoid arthritis treated with subcutaneous tocilizumab: results from a randomized, controlled trial (COMP-ACT). Arthritis Rheumatol 2018;70:1200-8.

33. Peterfy CG, Olech E, DiCarlo JC, Merrill JT, Countryman PJ, Gaylis NB. Monitoring cartilage loss in the hands and wrists in rheumatoid arthritis with magnetic resonance imaging in a multi-center clinical trial: IMPRESS (NCT00425932). Arthritis Res Ther 2013;15:R44.

34. Østergaard M, Peterfy C, Conaghan P, McQueen F, Bird P, Ejbjerg $\mathrm{B}$, et al. OMERACT rheumatoid arthritis magnetic resonance imaging studies. Core set of MRI acquisitions, joint pathology definitions, and the OMERACT RA-MRI scoring system. J Rheumatol 2003;30:1385-6.

35. Peterfy CG, DiCarlo JC, Olech E, Bagnard MA, Gabriele A, Gaylis $\mathrm{N}$. Evaluating joint-space narrowing and cartilage loss in rheumatoid arthritis by using MRI. Arthritis Res Ther 2012;14:R131.

36. Bruynesteyn K, Boers M, Kostense P, van der Linden S, van der Heijde D. Deciding on progression of joint damage in paired films of individual patients: smallest detectable difference or change. Ann Rheum Dis 2005;64:179-82.

37. Peterfy C, Emery P, Tak PP, Østergaard M, DiCarlo J, Otsa K, et al. MRI assessment of suppression of structural damage in patients with rheumatoid arthritis receiving rituximab: results from the randomised, placebo-controlled, double-blind RA-SCORE study. Ann Rheum Dis 2016;75:170-7.

38. Smolen JS, van der Heijde DM, Aletaha D, Xu S, Han J, Baker D, et al. Progression of radiographic joint damage in rheumatoid arthritis: independence of erosions and joint space narrowing. Ann Rheum Dis 2009;68:1535-40.

39. Zangger P, Keystone EC, Bogoch ER. Asymmetry of small joint involvement in rheumatoid arthritis: prevalence and tendency towards symmetry over time. Joint Bone Spine 2005;72:241-7.

40. Yaku A, Hashimoto M, Furu M, Ito H, Yamakawa N, Yamamoto W, et al. Relationship between handedness and joint involvement in rheumatoid arthritis. Sci Rep 2016;6:39180.

41. Mo YQ, Yang ZH, He HN, Ma JD, Liang JJ, Zeng WK, et al. Magnetic resonance imaging of bilateral hands is more optimal than MRI of unilateral hands for rheumatoid arthritis. J Rheumatol 2018;45:895-904. 